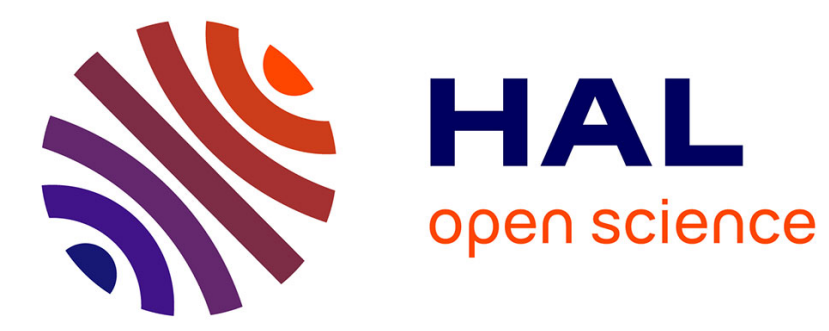

\title{
TSC and Broadband Dielectric Spectroscopy Studies of $\beta$ Relaxation in Phosphorus-Containing Dendrimers
}

Eric Dantras, Colette Lacabanne, Anne-Marie Caminade, Jean Pierre Majoral

\section{To cite this version:}

Eric Dantras, Colette Lacabanne, Anne-Marie Caminade, Jean Pierre Majoral. TSC and Broadband Dielectric Spectroscopy Studies of $\beta$ Relaxation in Phosphorus-Containing Dendrimers. Macromolecules, 2001, vol. 34 ( $\mathrm{n}^{\circ} 12$ ), pp. 3808-3811. 10.1021/ma001740v . hal-01308053

\section{HAL Id: hal-01308053 \\ https://hal.science/hal-01308053}

Submitted on 27 Apr 2016

HAL is a multi-disciplinary open access archive for the deposit and dissemination of scientific research documents, whether they are published or not. The documents may come from teaching and research institutions in France or abroad, or from public or private research centers.
L'archive ouverte pluridisciplinaire HAL, est destinée au dépôt et à la diffusion de documents scientifiques de niveau recherche, publiés ou non, émanant des établissements d'enseignement et de recherche français ou étrangers, des laboratoires publics ou privés. 


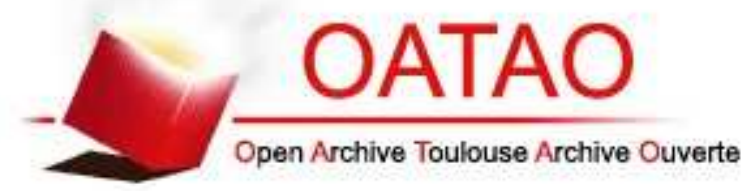

\section{Open Archive TOULOUSE Archive Ouverte (OATAO)}

OATAO is an open access repository that collects the work of Toulouse researchers and makes it freely available over the web where possible.

This is an author-deposited version published in : http://oatao.univ-toulouse.fr/ Eprints ID : 14313

To link to this article : DOI : $10.1021 / \mathrm{ma} 001740 \mathrm{v}$

URL : http://dx.doi.org/10.1021/ma001740v

To cite this version : Dantras, Eric and Lacabanne, Colette and

Caminade, Anne-Marie and Majoral, Jean-Pierre TSC and Broadband

Dielectric Spectroscopy Studies of $\beta$ Relaxation in Phosphorus-

Containing Dendrimers. (2001) Macromolecules, vol. 34 ( $\left.{ }^{\circ} 12\right)$. pp.

3808-3811. ISSN 0024-9297

Any correspondance concerning this service should be sent to the repository administrator: staff-oatao@ listes-diff.inp-toulouse.fr 


\section{TSC and Broadband Dielectric Spectroscopy Studies of $\boldsymbol{\beta}$ Relaxation in Phosphorus-Containing Dendrimers}

\section{E. Dantras and C. Lacabanne*}

CIRIMAT, Laboratoire de Physique des Polymères, Université Paul Sabatier, 31062 Toulouse Cedex 04, France

\section{A. M. Caminade and J. P. Majoral}

Laboratoire de Chimie de Coordination, 31077 Toulouse Cedex 04, France

Introduction. With their self-similar architectures, dendrimers constitute good models of complex structures. After Vögtle's results, ${ }^{1}$ further investigations have intended to increase the generation number. ${ }^{1,2}$ The state of the art is reached with phosphorus-containing dendrimers $^{3}$ (12th generation). The aim of this work is to analyze the evolution of molecular mobility upon increasing of generation. Thanks to complementary dielectric techniques as thermostimulated currents (TSC) and dynamic dielectric spectroscopy (DDS), the mechanism of dipolar polarization and its evolution as a function of the generation of dendrimers will be studied. DDS shows the shift of relaxation mode on a wide frequency and temperature range as being shown previously. ${ }^{5-8}$ Owing to its low equivalent frequency and its high sensibility, TSC experiments give complementary information on the elementary components of the complex relaxation. Moreover by using fractional polarization, the experimental distribution function of the activation parameters has been determined. In this communication, we focus on low-temperature relaxations of phosphorus-containing dendrimers of generations 0,1 , and 2 .

Experimental Section. Phosphorus-containing dendrimers are characterized by a regularly branched treelike architecture and strongest dipolar moment values found in dendrimers ${ }^{3}$ (for example $\mu=1.082 \times$ $10^{-28} \mathrm{C} \cdot \mathrm{m}$ for a generation number $g=11$ ). From a phosphorus core constituted by the strong $\mathrm{P}=\mathrm{S}$ dipole, these dendrimers were synthesized by a convergent process which consists on iteration of chemical steps. On the same core, radially branched layers were attached (Figure 1). Dendrimers were synthesized generation after generation. Details of synthesis of this amorphous polymers were published elsewhere. ${ }^{3,4}$ Numbering of these compounds hereafter will be done as follows: $\left[G_{g}^{\prime}\right]$ in which $g$ is the number of generation-here $g=$ 0,1 , and 2-and $G^{\prime}$ corresponds to a dendrimer with terminal aldehyde groups. All the studied samples are available as powder. For $g=0$, no calorimetric manifestation of glass transition has been pointed out. For $g$ $=1$ and $g=2$, the glass transitions $T_{\mathrm{g}}$ of the studied phosphorus-containing dendrimers are 346 and $395 \mathrm{~K}$ respectively. In the case of DDS, the sample is constituted by a thin layer of powder $(100 \pm 10 \mu \mathrm{m})$. For TSC experiments, slightly compressed pellets of $800 \pm 10 \mu \mathrm{m}$ thickness were directly inserted between electrodes.

\footnotetext{
* Corresponding author. E-mail: lacabane@cict.fr.
}

Broadband dielectric measurements were performed using a NOVOCONTROL BDS400 covering a frequency range of $10^{-2}$ to $3 \times 10^{6} \mathrm{~Hz}$ with 10 points per decade. Experiments were carried out with a temperature range 123-373 K. Dielectric isotherms spectra were measured every $5 \mathrm{~K}$. Before each frequency scan, temperature was kept constant to within $\pm 0.2 \mathrm{~K}$. The real $\epsilon_{T}^{\prime}$ and imaginary $\epsilon_{T}^{\prime \prime}$ parts of the relative complex permittivity $\epsilon_{T}^{*}$, were measured as a function of frequency $F$ at a given temperature $T$.

Complex TSC spectra and fractional polarization analysis were carried out on a Thermold TSC/RMA spectrometer. For global experiments, the sample was polarized by an electrostatic field $E_{\mathrm{p}}=400 \mathrm{kV} \cdot \mathrm{m}^{-1}$ during $t_{\mathrm{p}}=2$ min over a temperature range from the polarization temperature $T_{\mathrm{p}}=173 \mathrm{~K}$ down to the freezing temperature $T_{0}=93 \mathrm{~K}$. Then the field was turned off and the depolarization current was recorded with a constant heating rate $\left(q_{\mathrm{h}}=+7 \mathrm{~K} \cdot \mathrm{min}^{-1}\right)$, so that the equivalent frequency of the TSC spectrum was $f_{\text {eq }}$ $\sim 10^{-3}-10^{-4} \mathrm{~Hz}$. TSC experiments are complementary from DDS spectroscopy on the low-frequency side. For windowing experiments (ith elementary peak), the polarizing field was applied for $t_{\mathrm{p}}=2 \mathrm{~min}$ at $T_{\mathrm{p}}^{i}$. Then the sample was short-circuited at $T_{\mathrm{d}}^{i}=T_{\mathrm{p}}^{i}-\Delta T_{\mathrm{p}}$ and the temperature was maintained constant for $t_{\mathrm{d}}=t_{\mathrm{p}}$. Then the sample was cooled at $T_{0}^{i}=T_{\mathrm{p}}^{i}-50 \mathrm{~K}$, and the depolarization current was recorded in the same way as for the complex mode. Two types of windowing experiments ${ }^{11,12}$ were carried out: narrow poling windows $\left(\Delta T_{\mathrm{p}} \leq 5 \mathrm{~K}\right)$ for isolating elementary processes and large poling windows $\left(\Delta T_{\mathrm{p}} \geq 20 \mathrm{~K}\right)$ for the "cleaning process". Wide poling windows might allow us to exhibit the various components of relaxation modes and narrow poling windows give elementary TSC spectra that can be analyzed by the hypothesis of a single relaxation time.

Results and Discussion. Figure 2 displays the dielectric loss spectra of the low-temperature relaxation mode for $g=0$ (Figure 2a) and $g=2$ (Figure 2b) of phosphorus-containing dendrimers. Experimental data are fitted by the Havriliak-Negami (HN) function ${ }^{9,10}$ without any additional conductivity term

$$
\epsilon_{\mathrm{T}}^{*}(\omega)=\epsilon_{\infty}+\frac{\epsilon_{\mathrm{st}}-\epsilon_{\infty}}{\left[1+\left(i \omega \tau_{\mathrm{HN}}\right)^{\left.\alpha_{\mathrm{HN}}\right]^{\beta \mathrm{HN}}}\right.}
$$

where $\epsilon_{\infty}$ is the relative real permittivity at infinite frequency, $\epsilon_{\text {st }}$ is the relative real permittivity at null frequency, $\tau_{\mathrm{HN}}$ is the relaxation time, $\omega$ is the angular frequency, and $\alpha_{\mathrm{HN}}$ and $\beta_{\mathrm{HN}}$ are the Havriliak-Negami parameters. Numerical values of $\mathrm{HN}$ parameters are reported in Table 1.

For $g=0$, the dielectric loss profile confirms previous data on different dendritic macromolecules: ${ }^{5}$ a quasiDebye mode $\beta^{\left[G_{0}^{\prime}\right]}$ is pointed out. Since the isotherm $T=$ $248 \mathrm{~K}$, conductivity $\sigma$ appears on the low-frequency tail of $\epsilon_{T}^{\prime \prime}(\omega)$. Nevertheless, it does not modify the HavriliakNegami fitting.

For $g=1$ and $g=2$, two relaxation regimes are observed: $\left(\alpha^{\left[G_{1}^{\prime}\right]} ; \alpha^{\left[G_{2}^{\prime}\right]}\right)$ the dielectric manifestation of glass transition and a low-temperature mode $\left(\beta^{\left[G_{1}^{\prime}\right]}\right.$; 

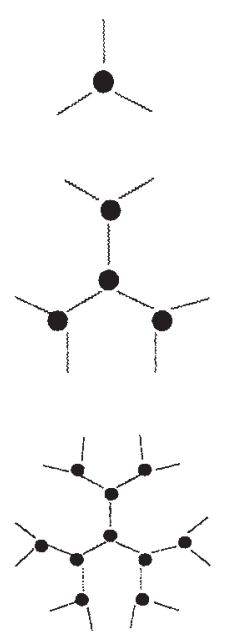
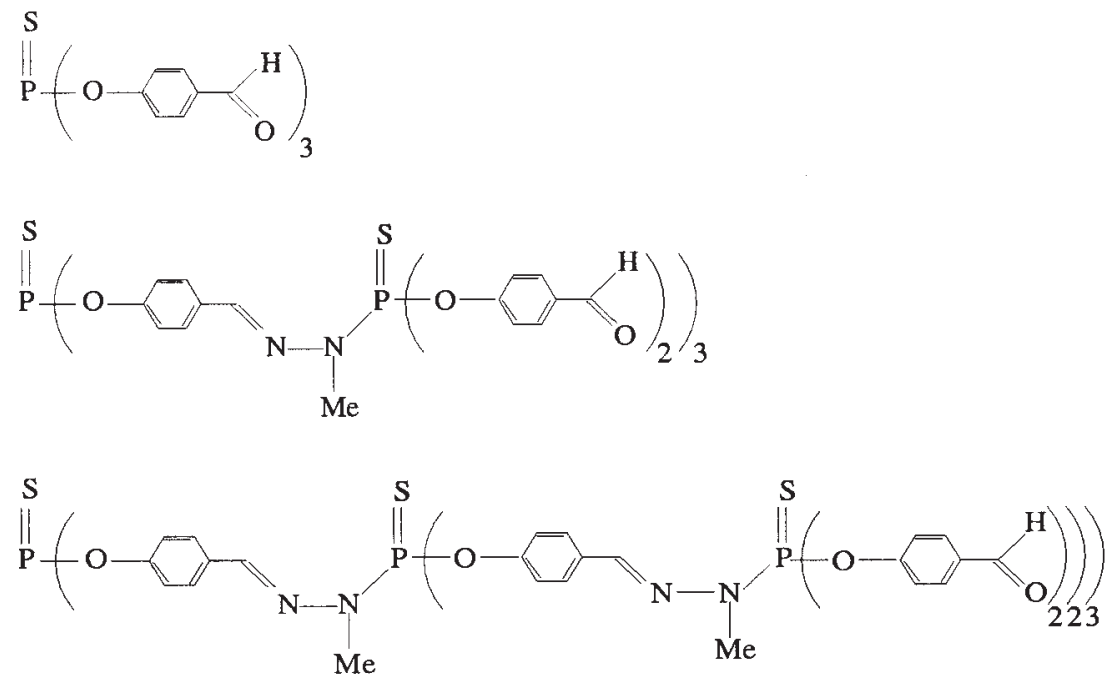

Figure 1. Scheme of phosphorus-containing dendrimer architectures (points $(\bullet)$ symbolize $\mathrm{P}=\mathrm{S}$ groups) and molecular structures for $g=0,1$, and 2 (respectively $\left[G_{0}^{\prime}\right],\left[G_{1}^{\prime}\right]$, and $\left[G_{2}^{\prime}\right]$ ).
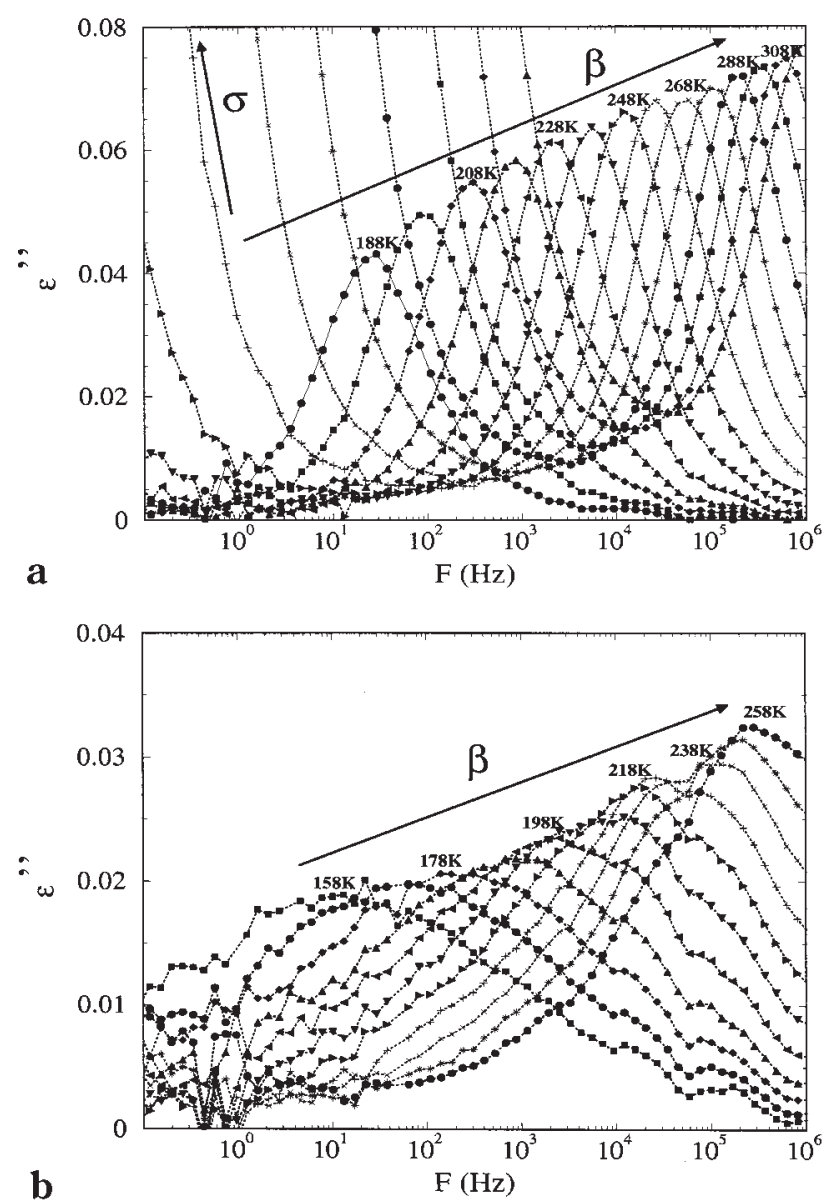

Figure 2. (a) Frequency and temperature dependence of the dielectric energy loss for the $\beta$-mode of $\left[G_{0}^{\prime}\right]$. (b) Frequency and temperature dependence of the dielectric energy loss for the $\beta$-mode of $\left[G_{2}^{\prime}\right]$.

$\left.\beta^{\left[G_{2}^{\prime}\right]}\right)$. For $g=0$, the sample exhibiting no glass transition, no $\alpha$ dielectric relaxation is observed. Contrarily, all studied phosphorus-containing dendrimers have a secondary $\beta$ relaxation mode. $\beta^{\left[G_{0}^{\prime}\right]}, \beta^{\left[G_{1}^{\prime}\right]}$, and $\beta^{\left[G_{2}^{\prime}\right]}$ modes
Table 1. Havriliak-Negami Parameters (Variation of HN Parameters with Temperature) for the Various Generations

\begin{tabular}{clll}
\hline HN param & $g=0\left[G_{0}^{\prime}\right]$ & $g=1\left[G_{1}^{\prime}\right]$ & $g=2\left[G_{2}^{\prime}\right]$ \\
\hline$\alpha_{\mathrm{HN}}$ & $0.90-0.971$ & $0.27-0.53$ & $0.28-0.41$ \\
$\beta_{\mathrm{HN}}$ & $0.912-1.0$ & $0.85-1.0$ & 1.0
\end{tabular}

are characterized by relaxation times with an Arrhenius-like dependence

$$
\tau(T)=\tau_{0} \exp \frac{\Delta H}{R T}
$$

where $R$ is the ideal gas constant, $\tau_{0}$ is the preexponential factor, and $\Delta H$ is the activation enthalpy. $\tau_{0}$ is on the order of magnitude of $\sim 10^{-13} \mathrm{~s}$.

According to the Eyring relationship

$$
\tau_{0}=\frac{h}{k_{\mathrm{B}} T} \exp -\frac{\Delta S}{R}
$$

where $h$ is the Planck constant, $k_{\mathrm{B}}$ is the Boltzmann constant, and $\Delta S$ is the activation entropy. For $\left[G_{0}^{\prime}\right]$, $\left[G_{1}^{\prime}\right]$, and $\left[G_{2}^{\prime}\right], \Delta S$ is near zero, and $\Delta H$ takes the values $\Delta H=40.4,32.6$, and $34.9 \mathrm{~kJ} \cdot \mathrm{mol}^{-1}$ respectively. This parameter is strongly dependent upon the generation. In others dendrimers ${ }^{6,7,8}$ activation enthalpies of $\beta$-modes vary from 16 to $80 \mathrm{~kJ} \cdot \mathrm{mol}^{-1}$ for $g=0$ and $g=$ 2 , respectively. This variation has been attributed to differences in their physical structure. In phosphoruscontaining dendrimers, the activation enthalpy of $\left[G_{0}^{\prime}\right]$ remains of the same order of magnitude than for $\left[G_{1}^{\prime}\right]$ and $\left[G_{2}^{\prime}\right]$. It is also important to note that the single peak of $\left[G_{0}^{\prime}\right]$ is perfectly explained by the existence of a single mobile dipolar species which is the aldehyde end group. The low-temperature mode $\beta^{\left[G_{G}\right]} / \beta^{\left[G_{2}^{\prime}\right]}$ occurs in the same temperature range than $\beta^{\left[G_{0}^{\prime}\right]}$, but its halfwidth increases: HN parameters related to mode width vary from $\alpha_{\mathrm{HN}}\left(\left[G_{0}^{\prime}\right]\right)=0.90-0.971$ to $\alpha_{\mathrm{HN}}\left(\left[G_{2}^{\prime}\right]\right)=0.28-$ 0.41 (cf. Table 1). The hypothesis of an additional dipolar relaxation is proposed in order to explain this important 

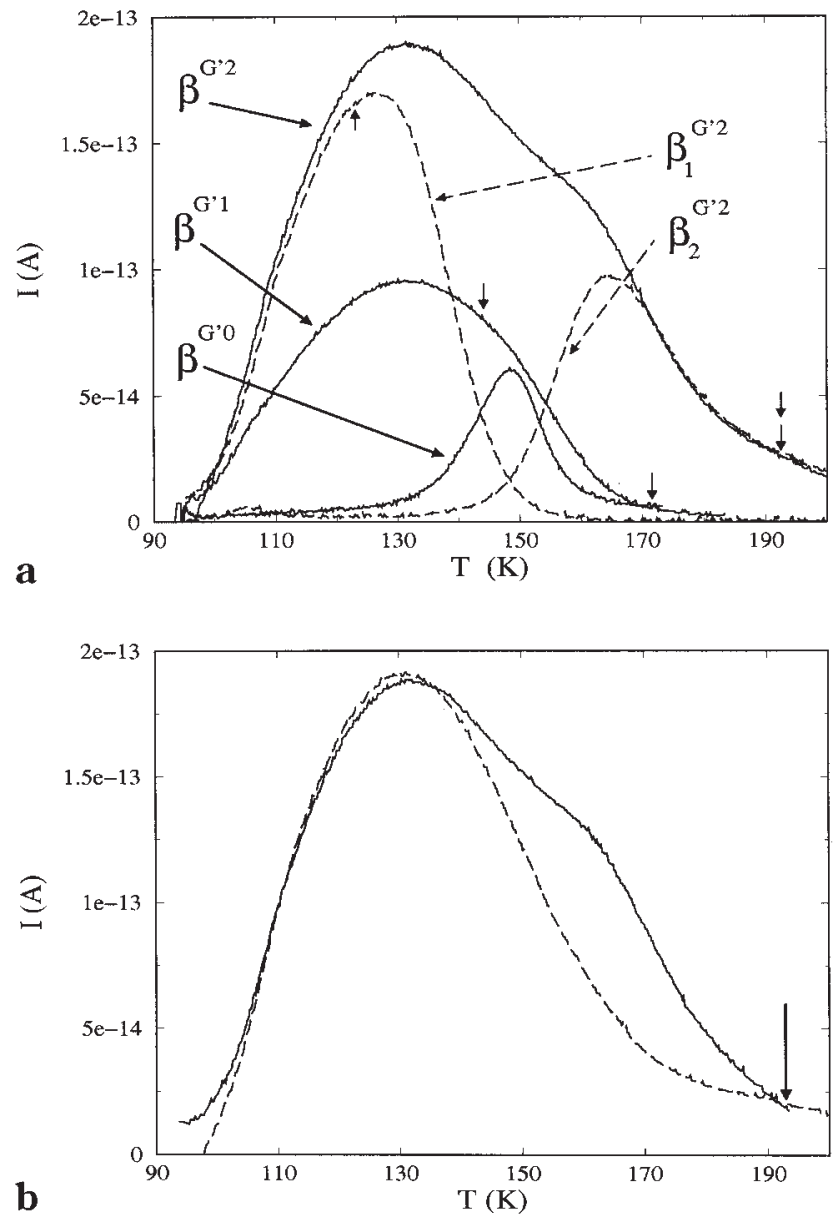

Figure 3. (a) Global TSC spectra of $\left[G_{0}^{\prime}\right],\left[G_{1}^{\prime}\right]$ and $\left[G_{2}^{\prime}\right]$ (full line). Experimental resolution of $\left[G_{2}^{\prime}\right]$ (long-dashed line) $\left(\Delta T_{\mathrm{p}}\right.$ $\geq 20 \mathrm{~K})$. The small arrows indicate the polarization temperatures. (b) Global TSC spectra of $\left[G_{2}^{\prime}\right]$ (full line) after thermal treatment and global TSC spectra of [ $\left.G_{2}^{\prime}\right]$ (long-dashed line) before thermal treatment. The arrow indicates the polarization temperature.

Table 2. Temperature Dependence of the Maximum Current $\left(i_{\mathrm{m}}\right)$, the Pre-Exponential Factors $\left(\tau_{0}\right)$, Activation Enthalpy, and Activation Entropy $(\Delta H$ and $\Delta S)$ of Relaxation Times Associated with the Elementary Peaks for $g=0$

\begin{tabular}{lcccc}
\hline $\begin{array}{c}T_{\mathrm{m}} \\
(\mathrm{K})\end{array}$ & $\begin{array}{c}\Delta H \\
\left(\mathrm{~kJ} \cdot \mathrm{mol}^{-1}\right)\end{array}$ & $\begin{array}{c}\tau_{0} \\
(\mathrm{~s})\end{array}$ & $\begin{array}{c}\Delta S \\
\left(\mathrm{~J} \cdot \mathrm{mol}^{-1} \cdot \mathrm{K}^{-1}\right)\end{array}$ & $\begin{array}{c}i_{\mathrm{m}} \\
\left(10^{-14} \mathrm{~A}\right)\end{array}$ \\
\hline 141 & 27.9 & $1.7 \times 10^{-9}$ & -70.8 & 1.13 \\
143.15 & 31.8 & $1.5 \times 10^{-10}$ & -50.8 & 2.4 \\
144 & 39.5 & $2.9 \times 10^{-13}$ & 11.3 & 3.6 \\
146 & 41.4 & $5.7 \times 10^{-14}$ & 14.5 & 4.2
\end{tabular}

broadening. A more detailed analysis of the complex relaxation modes, was carried out by TSC experiments.

Figure 3a shows the complex TSC spectrum in full line of phosphorus-containing dendrimers of generations 0,1 , and 2 . The polarization temperatures are indicated by the small arrows on the figure. The global TSC spectrum for $g=0$ presents a narrow peak, whose maximum is located at $149 \mathrm{~K}$. Fractional polarization with $\Delta T_{\mathrm{p}}=5 \mathrm{~K}$, exhibits a quasi-non-distributed mode. The temperature dependence of relaxation times is expressed by an Arrhenius equation (eq 2). Equations 2 and 3 permit us to extract $\Delta S$ and $\Delta H$, and these values are listed in Table 2 . Let us consider the major contribution component of this mode located at $T_{\mathrm{m}}=$ $146 \mathrm{~K}: \tau_{0}$ is close to $10^{-14} \mathrm{~s}$, which is coherent with DDS data. Consequently, this mode has been assigned to local dipolar relaxation.

In the case of $g=1$, a single mode is observed near $T_{\mathrm{m}}=131 \mathrm{~K}$. Taking as reference $G_{0}^{\prime}$, both characteristics half-width $\left(\Delta_{1 / 2}\right)$ and maximum current $\left(I_{\mathrm{m}}\right)$ of the peak slightly increase (from $\Delta_{1 / 2}\left(\left[G_{0}^{\prime}\right]\right) \sim 20 \mathrm{~K}$ to $\Delta_{1 / 2}$ $\left(\left[G_{1}^{\prime}\right]\right) \sim 40 \mathrm{~K}$, and $I_{\mathrm{m}}\left(\left[G_{0}^{\prime}\right]\right) \sim 6 \times 10^{-14}$ A to $I_{\mathrm{m}}\left(\left[G_{1}^{\prime}\right]\right) \sim$ $\left.1 \times 10^{-13} \mathrm{~A}\right)$. The peak temperature maximum is shifted toward lower temperature.

Contrarily to the modes observed for $g=0$ and $g=1$, the one recorded for $g=2$ is metastable. After a series of scans at the same rate in the investigated temperature range, it stabilizes and gives the spectrum reported as a solid line in parts $a$ and $b$ of Figure 3. After poling the virgin dendrimers, a single peak is recorded (dashed line in Figure $3 b)$. The higher temperature component has the same behavior than relaxation processes due to physical aging while the low-temperature component has the characteristics of a relaxation associated with a secondary transition.

To isolate both components, the windowing technique ("cleaning process") has been applied.

The polarization temperatures are indicated by small arrows on the Figure 3a. The complex TSC spectrum has been resolved by this technique into two submodes (dashed line in Figure 3a): first one $\beta_{1}{ }^{\left[G_{2}^{\prime}\right]}$ near $T_{1}=$ $128 \mathrm{~K}$ and a second one $\beta_{2}{ }^{\left[G_{2}^{\prime}\right]}$ near $T_{2}=163 \mathrm{~K}$. As expected, this complex mode has two major components. Their envelope (dashed line) follows the same variation as the complex mode (full line) of $\left[G_{2}^{\prime}\right]$. But neither $\beta_{1}{ }^{\left[G_{2}^{\prime}\right]}$ nor $\beta_{2}{ }^{\left[G_{2}^{\prime}\right]}$ can be compared with $\beta^{\left[G_{0}^{0}\right]}$ : temperature positions $\left(\Delta T\left(\beta_{1,2}{ }^{\left[G_{2}^{\prime}\right]} \beta^{\left[G_{0}^{\prime}\right]}\right) / 20 \mathrm{~K}\right)$ and intensities are quite different. The analysis of the lower temperature component of $\left[G_{2}^{\prime}\right]$ shows that it has a common origin with the relaxation mode observed in $\left[G_{0}^{\prime}\right]$. The complexity of the relaxation modes indicates the existence of interactions with other dipolar species, most probably $\mathrm{P}=\mathrm{S}$. The substitution of a $\mathrm{P}=\mathrm{S}$ core by a $\mathrm{P}=\mathrm{O}$ core for $g=0$ shows that there is a significant interaction with this group. Indeed, TSC experiments indicate a lowtemperature shift of $\sim 20 \mathrm{~K}$ of the very narrow mode. Considering the mobility and the polarity of the aldehyde groups, they might be responsible for the $\beta$ relaxation modes. To check this hypothesis, a comparative study of dendrimers without aldehyde end groups has been performed (in the case of the $\mathrm{P}=\mathrm{O}$ core): the $\beta$ mode does not exist. So, the $\beta$ mode has been assigned to local movements of aldehyde end groups. The higher temperature component requires local order inherent with physical aging so that it has been associated with a structural relaxation.

Conclusion. Combined TSC and DDS studies allow us to follow the temperature and frequency dependence of the $\beta$ relaxation mode of phosphorus-containing dendrimers. Dipolar nature of the relaxation modes has been shown. For $\left[G_{0}^{\prime}\right]$, a narrow relaxation mode is observed: this is coherent with the existence of a single mobile dipolar species, i.e., aldehyde end groups. Those dipolar species interact with the $\mathrm{P}=\mathrm{S}$ dipolar core. The relaxation mode found in $\left[G_{0}^{\prime}\right]$ exists also in $\left[G_{1}^{\prime}\right]$ and $\left[G_{2}^{\prime}\right]$ in the same temperature range. The activation enthalpies remains of the same order of magnitude than for $\left[G_{0}^{\prime}\right]$. The slight modification of its characteristic parameters has been associated with differences in the interaction with $\mathrm{P}=\mathrm{S}$ groups. An additional submode is also observed in $\left[G_{2}^{\prime}\right]$ in the same temperature range: due to its metastability, it might be ascribed to a 
will be extended to the high-temperature range in order to analyze more delocalized molecular mobility. We also plan to investigate dendrimers of the same series corresponding to higher generations, to compare them with equivalent linear and hyper-branched phosphoruscontaining macromolecules.

\section{References and Notes}

(1) Buhleier, E. W.; Wehner, W.; Vögtle, F. Synthesis 1978, $155-158$.

(2) Fischer, M.; Vögtle, F. Angew. Chem., Int. Ed. Engl. 1999, $38,884-905$.

(3) Lartigue, M. L.; Donnadieu, B.; Galliot, G.; Caminade, A.M.; Majoral, J.-P.; Fayet, J.-P. Macromolecules 1997, 30, 7335-7337.
Springer-Verlag: Berlin and Heidelberg, Germany, 1998; Vol. 197, pp 79-124.

(5) Trahash, B.; Frey, H.; Lorenz, K.; Stühn, B. Colloid. Polym. Sci. 1999, 1186-1192.

(6) Hurve, S. A.; Appelhans, D.; Prigann, J.; Voit, B. I.; Kremer, F. Macromolecules 2000, 33, 3762-3766.

(7) Emran, S. K.; Newkome, G. R.; Weis, C. D.; Harmon, J. P J. Polym. Sci., Part B 1999, 37, 2025-2038.

(8) Trahasch, B.; Stühn, B.; Frey, H.; Lorenz, K. Macromolecules 1999, 32, 1962-1966.

(9) Havriliak, S.; Negami, S. J. Polym. Sci., Part C 1966, 14, 99-117.

(10) Havriliak, S.; Negami, S. J. Polym. 1967, 8, 161-210

(11) Chatain, D.; Gautier, P.; Lacabanne, C. J. Polym. Sci., Phys. Ed. 1973, 11, 1631-1640.

(12) Teyssèdre, G.; Lacabanne, C. J. Phys. D: Appl. Phys. 1995, $28,1478-1487$ 